\title{
The Effect of Processing Parameters on Ferromanganese Alloy Carbon Content in
}

\section{Mamatwan Ore Reduction}

\section{Theresa Coetsee}

e-mail: theresa.coetsee@up.ac.za

Department of Materials Science and Metallurgical Engineering, University of Pretoria, South Africa

\begin{abstract}
Industrial production of medium carbon ferromanganese is accomplished by decarburisation of high carbon ferromanganese in an oxygen blown converter. In this study the possible in situ refinement of high carbon ferromanganese was tested in carbon deficient mixtures of pre-reduced Mamatwan ore, coal char and silica flux reacted at furnace temperatures of $1450^{\circ}-1550^{\circ} \mathrm{C}$. The resultant phase chemistry was analysed and interpreted with the aid of thermochemical calculations. Production of carbon unsaturated ferromanganese alloy in the AlloyStream process is explained with reference to laboratory experimental results.
\end{abstract}

Keywords: reduction; manganese; mineralogy; basicity

\section{Introduction}

Medium carbon ferromanganese (MCFeMn) is produced by decarburisation of high carbon ferromanganese (HCFeMn) in an oxygen blown converter. This process requires high temperatures up to $1750^{\circ} \mathrm{C}$ and vigorous mixing to drive process kinetics. One of the disadvantages is high losses of manganese to slag an off gas, reaction products which must be recycled to the high carbon ferromanganese furnace to improve overall manganese recovery levels (Habashi, 1997). If the ferromanganese alloy carbon level could be managed to lower levels already in the primary production process of HCFeMn, the need for the current high intensity, low manganese recovery converter process step may be negated.

Terayama and Ikeda (1985) reacted pure $\mathrm{MnO}$ and $\mathrm{C}$ at the mole ratio of one $(\mathrm{mol} \mathrm{C} / \mathrm{mol} \mathrm{MnO}=1 / 1)$ at $1200^{\circ} \mathrm{C}$ and concluded, from XRD (X-ray diffraction) analyses of the reaction product, that the initially formed $\mathrm{Mn}_{7} \mathrm{C}_{3}$ was converted to $\mathrm{Mn}$ metal at complete reaction extent. When the carbon addition was increased to a mole ratio of 2.5, the product was $\mathrm{Mn}_{7} \mathrm{C}_{3}$, indicating that no conversion to $\mathrm{Mn}$ took place. The conclusion was that conversion of $\mathrm{Mn}_{7} \mathrm{C}_{3}$ took place according to reaction (1). From FactSage 6.4 thermochemical calculations, reaction (1) occurs at temperatures above $938^{\circ} \mathrm{C}$.

$\mathrm{Mn}_{7} \mathrm{C}_{3}+3 \mathrm{CO}_{2}=7 \mathrm{Mn}+6 \mathrm{CO}$

The AlloyStream process was originally developed to produce steel directly from mixed feed of iron ore, coal and fluxes, as described in U.S. patent 6146437 (Fourie, 2000). Therefore, the process provided conditions of higher oxygen potential in contact with the alloy to ensure minimal dissolution of carbon from coal into the alloy phase so that steel was produced and not cast iron. The process consisted of feeding $-10 \mathrm{~mm}$ raw material mixture through the furnace combustion zone (freeboard) onto a liquid alloy bath, forming heaps of reacted material; the heap material is heated at the heap top surface by heat generated from burning combustibles with oxygen enriched air in the freeboard. The combustibles consist of fuel gas, coal volatiles, coal carbon and reduction reaction product gas emanating from the heaps. Final reaction and smelting of the heap material is supported by energy transferred from the induction-heated alloy bath. 
The results of Terayama and Ikeda (1985) on MnO reduction and direct production of steel in the AlloyStream process led to the main objective of this work to test if medium carbon ferromanganese alloy may be produced by reaction of manganese ore at carbon deficient levels ( $\mathrm{mol} \mathrm{C} / \mathrm{mol} \mathrm{MnO}<1$ ), and investigate the attainable levels of manganese recovery to the alloy. In addition, the effect of reduction parameters was tested in terms of level of carbon addition, reaction temperature and reaction time.

The presence of gangue oxides and iron oxides in manganese ores results in a reaction set-up which is expected to be more complex than that used in the study by Terayama and Ikeda (1985). Mamatwan ore is used extensively in the local ferromanganese production industry. Mamatwan ore reduction follows a sequence of two to three distinctive reduction stages (Koursaris et al., 1983; Koursaris and See, 1979; Eric and Burucu, 1992). In the rapid first stage $\mathrm{CO}$ reduction of higher oxides of manganese and iron to $\mathrm{MnO}$ and $\mathrm{FeO}$ occurs. In the markedly slower second stage of reduction metallisation of $\mathrm{FeO}$ and $\mathrm{MnO}$ starts. Metallisation begins with metallic iron nucleation throughout the reduced ore particle, adjacent to solid monoxide particles within the liquid silicate slag (provided the temperature is high enough to form liquid slag). As manganese reduction progresses the iron nuclei are alloyed with manganese and carbon. In the third stage final reduction of $\mathrm{MnO}$ by carbon dissolved in the alloy phase occurs at the solid monoxide-alloy phase interface. The third stage has the lowest reduction rate, most likely due to the slow diffusion of $\mathrm{Mn}^{2+}$ ions in the monoxide phase, and/or liquid slag phase coating the monoxide phase (Eric and Burucu, 1992).

Once the alloy beads and manganese monoxide phase areas are encapsulated in the liquid silicate phase inside the reduced ore particle, reduction by $\mathrm{CO}$ gas is hindered, and reduction may proceed at the ore particle surface by solid carbon and carbon in alloy, and/or inside the reduced ore particle by carbon in alloy particles.

The Mamatwan ore used in this work contained braunite $\left(\mathrm{MnO} .3 \mathrm{Mn}_{2} \mathrm{O}_{3} . \mathrm{SiO}_{2}\right)$ as the main mineral, and minor minerals of carbonate type, kutnohorite $\left(\mathrm{Ca}(\mathrm{Mn}, \mathrm{Mg})\left(\mathrm{CO}_{3}\right)_{2}\right)$ and calcite $\left(\mathrm{CaCO}_{3}\right)$. The ore was pre-reduced to $\mathrm{MnO}$ and $\mathrm{FeO}$ to simplify the ore mineralogy and to eliminate the possible interference of $\mathrm{CO}_{2}$ gas from ore carbonate calcination in the reduction experiments. In the industrial production of high carbon ferromanganese the discard slag practise is applied to ensure maximum manganese recovery to the alloy from basic ores such as Mamatwan ore (Habashi, 1997). Therefore, input mixtures in this study were selected to form high basicity slag in accordance with the discard slag practice.

\section{Experimental}

\subsection{Raw materials}

Mixtures of pre-reduced Mamatwan ore (-6.3 mm), Eikeboom char (-2 mm) and silica flux (-1 $\mathrm{mm})$ were reacted at temperatures of $1450^{\circ} \mathrm{C}, 1500^{\circ} \mathrm{C}$ and $1550^{\circ} \mathrm{C}$. Analyses of pre-reduced Mamatwan ore and Eikeboom char are presented in Table 1 and Table 2. Chemical analyses of Mamatwan ore, char ash and silica flux were done by Inductively Coupled Plasma Optical Emission Spectrometry (ICP-OES) method. Bulk product metal carbon analyses and char ultimate analysis $(\mathrm{C}, \mathrm{H}, \mathrm{N})$ were done by combustion (LECO) analysis method.

Eikeboom coal was devolatilised at $1000^{\circ} \mathrm{C}$ under $\mathrm{N}_{2}$ atmosphere. Mamatwan ore was pre-reduced to $\mathrm{MnO}$ and $\mathrm{FeO}$ by reduction at $1000^{\circ} \mathrm{C}$ under $\mathrm{CO}$ atmosphere. The carbonates present in the Mamatwan ore was nearly fully calcinated, as indicated by low level for carbon analysed in the pre-reduced ore, expressed as $\mathrm{CaCO}_{3}$ in Table 1. The level of pre-reduction is confirmed by the total of the pre-reduced ore chemical analysis of 99 mass\% for the compounds as in Table 1.

Char addition in each mixture was calculated by mass balance for the target level of manganese metallisation from $\mathrm{MnO}, 100 \%$ iron metallisation from $\mathrm{FeO}$ in the ore and $\mathrm{Fe}_{2} \mathrm{O}_{3}$ in the char ash and flux, and $2 \% \mathrm{C}$ in the expected alloy mass, assuming the reduction reaction product gas consisted of $\mathrm{CO}$ only, and the only $\mathrm{CO}_{2}$ in 
the product gas was generated by calcination of the small quantities of $\mathrm{CaCO}_{3}$ and $\mathrm{MgCO}_{3}$ present in the silica flux (99 mass\% $\mathrm{SiO}_{2}$ ). The level of char addition was expressed as the mol ratio of carbon to reducible oxygen (C/O) to meaningfully present the importance of carbon addition, as compared to a mass\% carbon addition number. In the $(\mathrm{C} / \mathrm{O})$ value, reducible oxygen $(\mathrm{O})$ is the sum of the oxygen associated with $\mathrm{Mn}$ and Fe oxides, and $\mathrm{C}$ is the value from the ultimate analysis in Table 2 . Silica flux additions were made to attain the aim slag basicity of $\left(\% \mathrm{CaO} / \% \mathrm{SiO}_{2}\right)=\mathrm{B} 2=1.04$ and $(\% \mathrm{CaO}+\% \mathrm{MgO}) / \% \mathrm{SiO}_{2}=\mathrm{B} 3=1.34$, estimated to be sufficient for $\mathrm{MgO}$ saturation at $1500^{\circ} \mathrm{C}$ at $80 \%$ manganese recovery to the alloy. A summary of the experimental conditions is contained in Table 3.

Table 1: Mamatwan pre-reduced ore bulk chemical composition

\begin{tabular}{|l|c|}
\hline & Mass\% \\
\hline $\mathrm{MnO}$ & 62.37 \\
\hline $\mathrm{FeO}$ & 7.58 \\
\hline $\mathrm{SiO}_{2}$ & 7.73 \\
\hline $\mathrm{Al}_{2} \mathrm{O}_{3}$ & 0.29 \\
\hline $\mathrm{CaO}$ & 15.90 \\
\hline $\mathrm{MgO}$ & 4.59 \\
\hline $\mathrm{TiO}_{2}$ & 0.04 \\
\hline $\mathrm{K}_{2} \mathrm{O}$ & 0.03 \\
\hline $\mathrm{CaCO}$ & 0.50 \\
\hline $\mathrm{S}$ & 0.05 \\
\hline Total & 99.08 \\
\hline
\end{tabular}

Table 2: Eikeboom char bulk composition (mass percentages)

\begin{tabular}{|l|c|}
\hline \multicolumn{2}{|c|}{ Proximate analysis (dry basis) } \\
\hline Moisture & 0.1 \\
\hline Volatile matter & 0.4 \\
\hline Fixed carbon & 82.7 \\
\hline Ash & 16.9 \\
\hline \multicolumn{2}{|c|}{ Ultimate analysis (dry basis) } \\
\hline $\mathrm{C}$ & 79.8 \\
\hline $\mathrm{H}$ & 0.35 \\
\hline $\mathrm{N}$ & 1.11 \\
\hline $\mathrm{O}$ & 1.48 \\
\hline $\mathrm{S}$ & 0.36 \\
\hline \multicolumn{2}{|c|}{ Ash analysis (dry basis) } \\
\hline $\mathrm{SiO}_{2}$ & 54.50 \\
\hline $\mathrm{Al}_{2} \mathrm{O}_{3}$ & 36.10 \\
\hline $\mathrm{Fe}_{2} \mathrm{O}_{3}$ & 3.76 \\
\hline $\mathrm{TiO}_{2}$ & 2.00 \\
\hline $\mathrm{CaO}_{2}$ & 1.53 \\
\hline $\mathrm{MgO}_{2}$ & 0.41 \\
\hline $\mathrm{MnO}^{2}$ & 0.03 \\
\hline $\mathrm{Na}_{2} \mathrm{O}$ & 0.09 \\
\hline $\mathrm{K}_{2} \mathrm{O}$ & 0.56 \\
\hline $\mathrm{P}_{2} \mathrm{O}_{5}$ & 0.62 \\
\hline $\mathrm{Cr}_{2} \mathrm{O}_{3}$ & 0.23 \\
\hline $\mathrm{S}$ & 0.09 \\
\hline
\end{tabular}


Table 3: Feed material mixtures and furnace temperatures

\begin{tabular}{|c|c|c|c|c|c|c|}
\hline $\begin{array}{c}\text { Sample } \\
\text { Name }\end{array}$ & $\begin{array}{c}\text { mass\% } \\
\text { pre- } \\
\text { reduced } \\
\text { ore }\end{array}$ & $\begin{array}{c}\text { mass\% } \\
\text { Char }\end{array}$ & $\begin{array}{c}\text { mass\% } \\
\text { Silica }\end{array}$ & C/O & $\begin{array}{c}\text { Aim } \\
\% \mathrm{Mn} \\
\text { recovery }\end{array}$ & $\begin{array}{c}\text { *Furnace } \\
\text { Temperature } \\
\left({ }^{\circ} \mathrm{C}\right)\end{array}$ \\
\hline A & 84.2 & 10.1 & 5.7 & 0.79 & 70 & 1500 \\
\hline B & 82.8 & 11.8 & 5.5 & 0.94 & 85 & 1500 \\
\hline C & 81.4 & 13.4 & 5.2 & 1.08 & 100 & 1500 \\
\hline D & 82.8 & 11.8 & 5.5 & 0.94 & 85 & 1450 \\
\hline E & 82.8 & 11.8 & 5.5 & 0.94 & 85 & 1550 \\
\hline F & 82.8 & 11.8 & 5.5 & 0.94 & 85 & 1550 \\
\hline G & 82.8 & 11.8 & 5.5 & 0.94 & 85 & 1550 \\
\hline
\end{tabular}

*Furnace hot zone temperature

\subsection{Experimental set-up}

The sample mixture mass was \pm 50 gram, with 42.2 gram of pre-reduced ore as basis. The sample mixture was contained in an $\mathrm{MgO}$ crucible and introduced under Ar into the hot zone of the tube furnace, via the pedestal. The MgO crucible was held in an alumina safety crucible to protect the furnace tube in case of $\mathrm{MgO}$ crucible failure. After the requisite reaction period passed, the sample was lowered into a cooling box, and the slide gate separating the furnace tube and cooling box was closed. The sample was cooled under Ar. The cooled sample was set in epoxy to form a polished section, which was then halved. From one half polished section, the alloy was separated out for bulk analyses for \%Mn, \%Fe and \%C. The other half of the polished section was analysed by SEM (Scanning electron microscopy) using wavelength-dispersive X-ray spectrometry (WDX) to characterise the sample phase chemistry.

Throughout the experiment, the product gas was analysed by mass spectrometer for $\mathrm{Ar}, \mathrm{CO}$ and $\mathrm{CO}_{2}$. The Argon carrier gas flow rate was measured before each experiment by using a soap bubble meter, and flow rate control was done by rotameter fed from an Ar bottle via a pressure regulator. Argon gas of $99.999 \%$ purity was used as carrier gas at a flow rate of $1028 \mathrm{~cm}^{3} / \mathrm{min}$. The Ar gas was cleaned by passing through anhydrous $\mathrm{CaSO}_{4}$ to remove water ("Drierite"), and through an "Oxyzorb" cartridge to remove oxygen. From the water cooled top lid of the furnace, the product gas passed through a filter to remove any dust particles present in the gas stream. The product gas flowed past a draw off point from which a continuous sample stream was drawn off to the mass spectrometer (VG Gaslab 300) for analyses, and the product gas then flowed through a bubbler to the vent. The mass spectrometer was calibrated prior to each set of experiments. The calibration gases used were $100 \% \mathrm{CO}, 100 \% \mathrm{Ar}$ and $10 \% \mathrm{CO}_{2}$-Ar, respectively.

\section{Results and discussion}

\subsection{Product analyses and features}

The product gas consisted mainly of $\mathrm{CO}$, as very little $\mathrm{CO}_{2}$ was measured in the product gas analyses. Samples $A$ to $\mathrm{E}$ were reacted until the $\mathrm{CO}$ concentration in the product gas dissipated to zero percent. The product gas analyses data for sample $\mathrm{E}$ is plotted in Figure 1. Due to the presence of both manganese and iron oxides in the feed mixture, it is not possible to allocate the $\mathrm{CO}$ quantities measured to a specific reduction reaction. The total oxygen content in the product gas does allow for monitoring the reaction extent over time in each experiment so that the relative performance under different reaction conditions may be compared. This information is plotted in Fig. 2 with percentage reduction expressed as the mass of oxygen in $\mathrm{CO}$ and $\mathrm{CO}_{2}$ in the product gas, as a percentage of the reducible oxygen in the feed mixture. A time marker is superimposed onto each curve, indicating the time taken to lift the sample to the furnace hot zone target position. This 
period of time was 35-40 minutes, at a lifting rate of typically $2 \mathrm{~cm} /$ minute. It is seen that sample A was lifted at a somewhat slower rate of $1.5 \mathrm{~cm} /$ minute. Reaction time information is summarised in Table 4 . Analyses of the bulk alloy recovered from one half of the polished section are summarised in Table 5. For samples F and $G$ the quantity of coalesced alloy was insufficient to conduct bulk chemical analyses. The alloy compositions of samples A to $E$ contain high levels of manganese and carbon, confirming that HCFeMn was formed as product alloy, despite the variation in $\mathrm{C} / \mathrm{O}$ in the feed mixtures. Therefore, the bulk alloy analyses confirmed that no bulk refinement of alloy carbon occurred at the experimental conditions used.

Figure 1: Product gas analyses data for sample $\mathrm{E}$

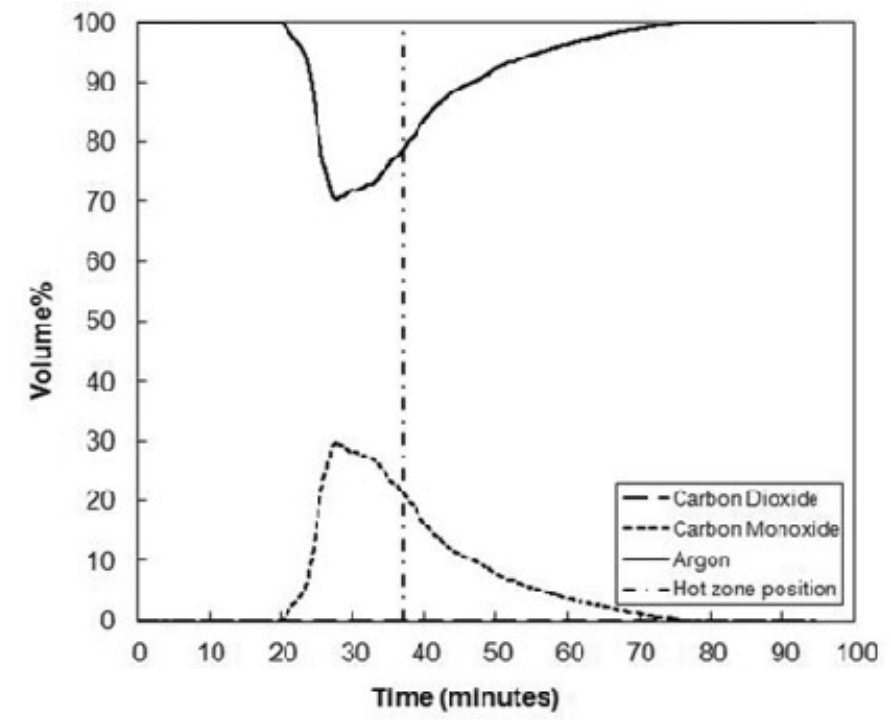

Figure 2: Percentage reduction vs. time

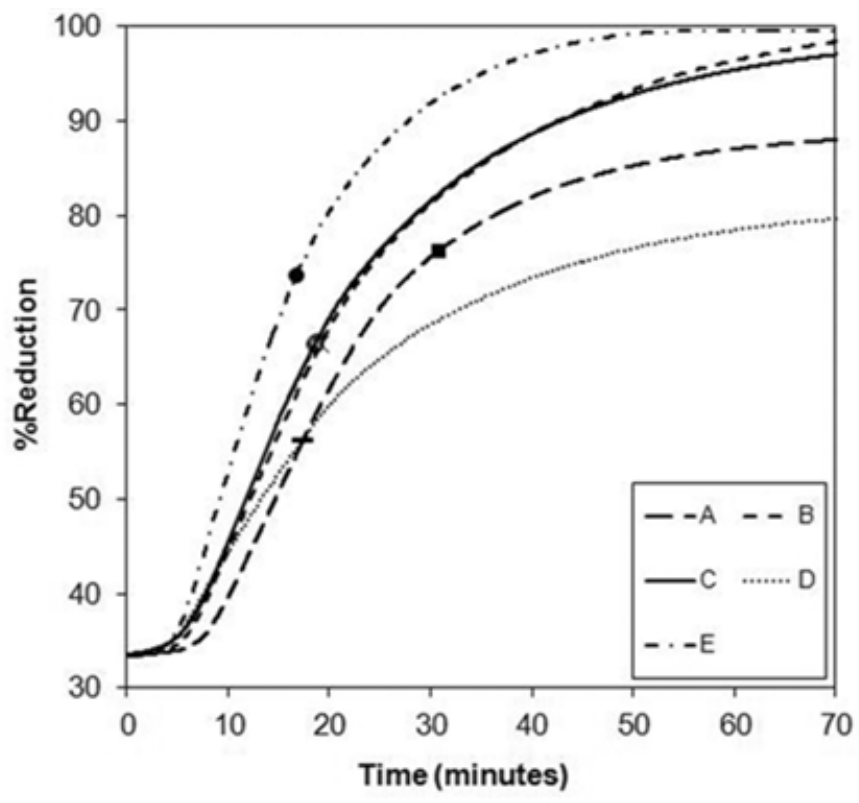

For samples $A$ to $E$, the maximum $C O$ concentration was measured before the sample reached the hot zone position as illustrated for sample $E$ in Figure 1. To further investigate this initial period of reaction, a sample 
was reacted for 40 minutes only (sample G, Table 4). This sample polished section may be compared to polished sections of samples $\mathrm{A}$ to $\mathrm{E}$, indicating that significant reduction of $\mathrm{MnO}$ and $\mathrm{FeO}$ to alloy occurred early on at lower temperatures in sample G. However, final reduction to high recovery levels to the alloy and bulk separation of slag and alloy did not occur, as in the case of samples A to $E$. These observations are clear from comparison of the relative size and coalescence of alloy in the polished section photographs in Figure 3 (a-f), illustrating the complex interaction of melting and reduction in manganese ore. Therefore, detailed investigation of reduction in manganese ores should include the study of morphological changes in the ore due to phase chemistry changes as reduction proceeds, to enable interpretation of reduction progress over time. These mineralogical details are discussed in the following section. Comparison of percentage reduction graphs in Figure 2 illustrates the dominant effect of temperature increase from $1450^{\circ} \mathrm{C}$ to $1550^{\circ} \mathrm{C}$ on the reduction rate (graphs for samples D, B and E). The effect of carbon addition was only observed at the lowest level of carbon addition ( $C / O=0.79$ ) in sample $A$, as compared to graphs for samples $B$ and $C$ at carbon addition levels of 0.94 and 1.08 , respectively.

Table 4: Reaction times (minutes)

\begin{tabular}{|c|c|c|c|c|c|c|}
\hline $\begin{array}{c}\text { Sample } \\
\text { Name }\end{array}$ & $\begin{array}{c}\text { Time to } \\
\text { first CO } \\
\text { formation }\end{array}$ & $\begin{array}{c}\text { Time to } \\
\text { hot } \\
\text { zone } \\
\text { position }\end{array}$ & $\begin{array}{c}\text { Total } \\
\text { reaction } \\
\text { time }\end{array}$ & C/O & $\begin{array}{c}\text { Aim } \\
\% \mathrm{Mn} \\
\text { recovery }\end{array}$ & $\begin{array}{c}\text { *Furnace } \\
\text { Temperature } \\
\left({ }^{\circ} \mathrm{C}\right)\end{array}$ \\
\hline A & 23 & 53 & 93 & 0.79 & 70 & 1500 \\
\hline B & 22 & 40 & 111 & 0.94 & 85 & 1500 \\
\hline C & 20 & 38 & 107 & 1.08 & 100 & 1500 \\
\hline D & 19 & 36 & 94 & 0.94 & 85 & 1450 \\
\hline E & 20 & 37 & 74 & 0.94 & 85 & 1550 \\
\hline F & 21 & 28 & 28 & 0.94 & 85 & 1550 \\
\hline G & 22 & 40 & 40 & 0.94 & 85 & 1550 \\
\hline
\end{tabular}

*Furnace hot zone temperature

Table 5: Bulk alloy analyses (mass\%)

\begin{tabular}{|c|c|c|c|c|c|c|c|}
\hline $\begin{array}{l}\text { Sample } \\
\text { Name }\end{array}$ & $\% \mathrm{Fe}$ & $\% \mathrm{Mn}$ & $\% \mathrm{C}$ & Total & $\mathrm{C} / \mathrm{O}$ & $\begin{array}{c}\text { Aim } \\
\text { \%Mn } \\
\text { recovery }\end{array}$ & $\begin{array}{c}\text { *Furnace } \\
\text { Temperature } \\
\left({ }^{\circ} \mathrm{C}\right)\end{array}$ \\
\hline$A$ & 12.0 & 79.9 & 7.76 & 99.7 & 0.79 & 70 & 1500 \\
\hline B & 12.0 & 76.5 & 8.73 & 97.3 & 0.94 & 85 & 1500 \\
\hline $\mathrm{C}$ & 10.5 & 80.3 & 8.04 & 98.8 & 1.08 & 100 & 1500 \\
\hline $\mathrm{D}$ & 13.1 & 73.1 & 7.99 & 94.2 & 0.94 & 85 & 1450 \\
\hline$E$ & 11.7 & 77.3 & 8.22 & 97.5 & 0.94 & 85 & 1550 \\
\hline $\mathrm{F}$ & \multicolumn{4}{|c|}{ Insufficient coalesced alloy } & 0.94 & 85 & 1550 \\
\hline G & \multicolumn{4}{|c|}{ Insufficient coalesced alloy } & 0.94 & 85 & 1550 \\
\hline
\end{tabular}


Figure 3: Photographs of polished sections

Sample A

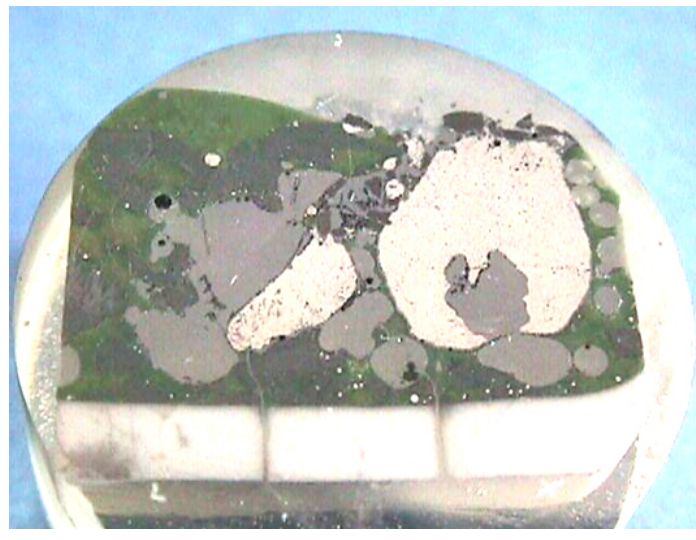

Sample C

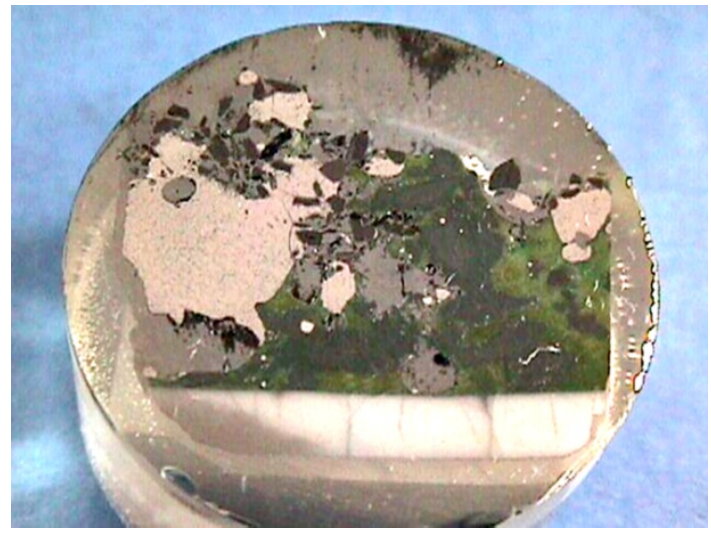

Sample E

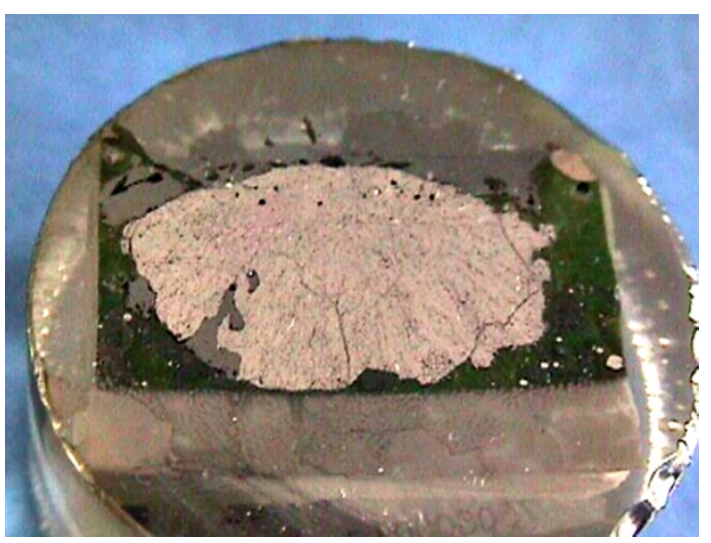

Sample B

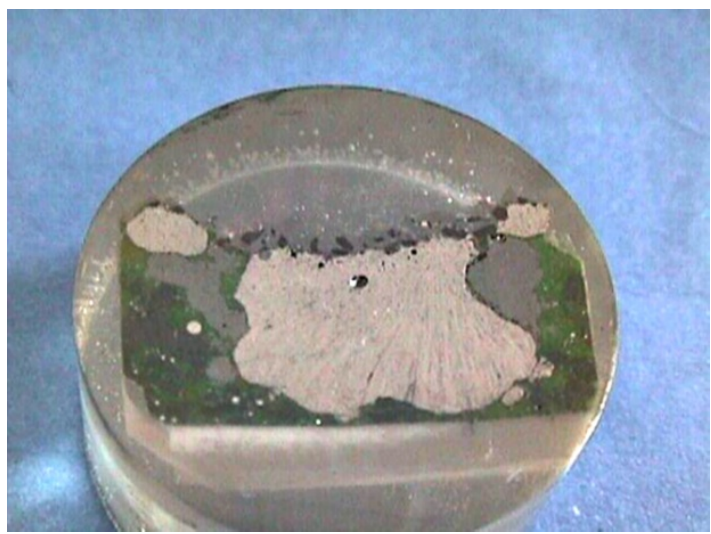

Sample D

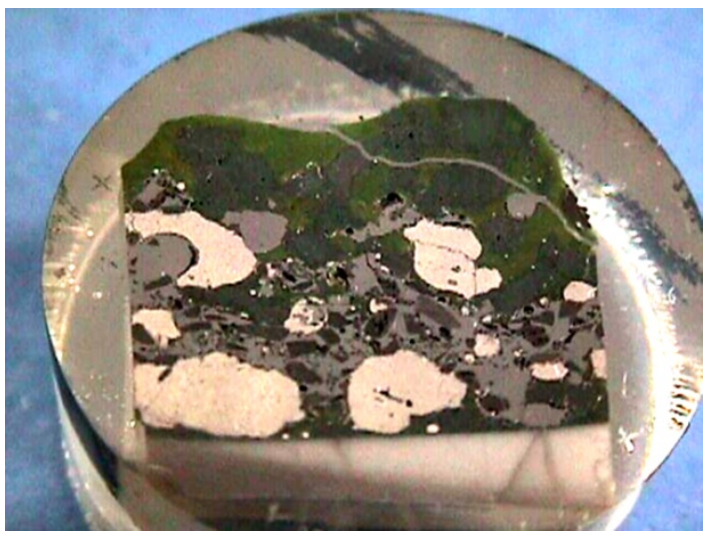

Sample G

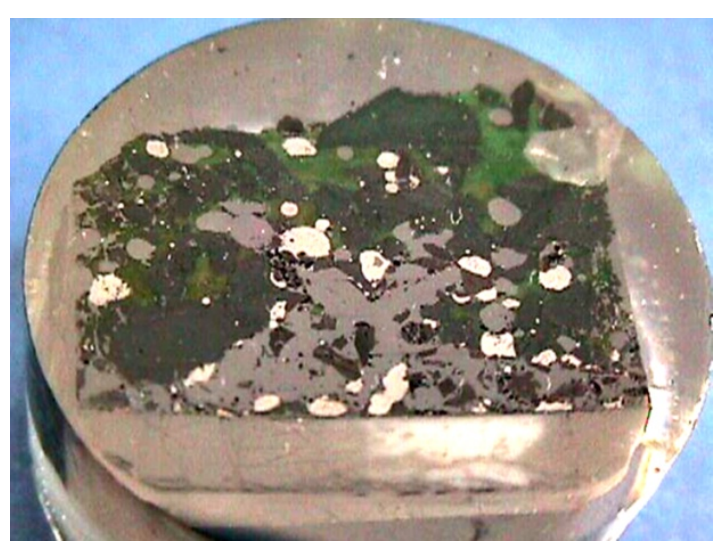




\subsection{Mass balance}

Mass loss values from the product gas analyses and mass loss measurements (sample mass before reaction minus sample mass after reaction) were compared to the mass loss values as calculated from a mass balance. Mass balance calculations were based on the following assumptions: \%Fe recovery to alloy is $100 \%$, only CO gas formed from reduction of oxygen from iron and manganese oxides, the level of \%Mn recovery to alloy was set to the level required to attain \% $\mathrm{Mn}$ in the alloy equal to the normalised bulk alloy analysis contained in Table 5. The calculated alloy analyses, alloy masses and percentage manganese recovery to alloy are summarised in Table 6. The comparative values are summarised in Figure 4. The calculated mass loss differed by a maximum of 1.7 grams from the measured mass loss for sample $C$. For samples $A$ to $E$, the mass balance calculation indicated insufficient quantities of carbon available to attain the alloy carbon analysis in Table 5. These values of mass carbon shortage are summarised in Table 6.

Figure 4: Mass loss values: measured vs. mass balance calculated

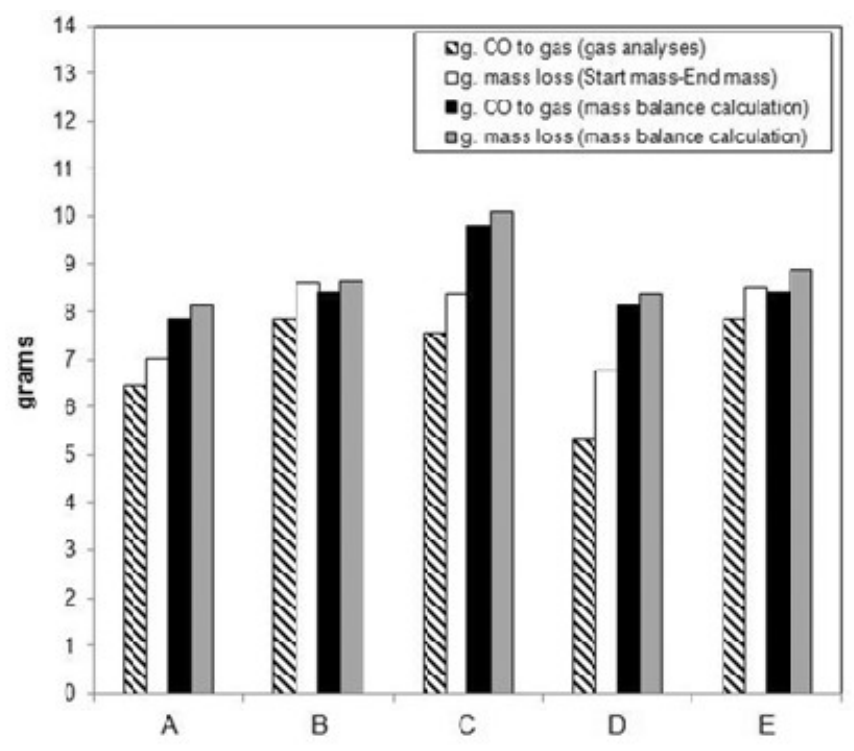

Table 6: Mass balance calculated values

\begin{tabular}{|c|c|c|c|c|c|c|c|c|}
\hline $\begin{array}{c}\text { Sample } \\
\text { Name }\end{array}$ & $\% \mathrm{Mn}$ & \%Fe & $\% \mathrm{C}$ & $\begin{array}{c}\text { g. C } \\
\text { deficit }^{1}\end{array}$ & $\begin{array}{c}\text { mol CO } \\
\text { measured }\end{array}$ & $\begin{array}{c}\text { mol CO } \\
\text { calculated }\end{array}$ & $\begin{array}{c}\text { \%Mn } \\
\text { recovery }\end{array}$ & $\begin{array}{c}\text { g. Alloy } \\
\text { calculated }\end{array}$ \\
\hline A & 80.2 & 15.8 & 3.99 & 0.61 & 0.28 & 0.23 & 63 & 16.0 \\
\hline B & 78.6 & 14.5 & 6.89 & 0.36 & 0.30 & 0.28 & 67 & 17.5 \\
\hline C & 81.2 & 12.5 & 6.34 & 0.37 & 0.35 & 0.27 & 81 & 20.4 \\
\hline D & 77.6 & 14.8 & 7.60 & 0.15 & 0.29 & 0.19 & 65 & 17.2 \\
\hline E & 79.6 & 14.2 & 6.19 & 0.40 & 0.30 & 0.28 & 69 & 17.9 \\
\hline
\end{tabular}

${ }^{1}$ mass of carbon required to increase \%C in to normalised analysed bulk alloy \%C shown in Table 5 


\subsection{Phase chemistry}

Phase chemical analyses of the product polished sections were done to further investigate the reaction products. Phase chemistry in the polished sections were analysed by SEM (Scanning electron microscopy) using wavelength-dispersive X-ray spectrometry (WDX). Equilibrium phase chemistry calculations were made with FactSage 6.4 thermochemical calculation software, using the FToxid and SGTE databases (Bale et al., 2002).

Because the experimental measurements indicate that molten phase development with heating time is an important aspect in manganese reduction from the ore, changes in slag phase chemistry was investigated in more detail. In Figure 5 changes in slag phase basicity and \% $\mathrm{MnO}$, measured by SEM, is plotted for each sample reacted.

Only sample F, reacted for 28 minutes, displayed a changing trend in analyses, from B3 basicity of 0.7 to 1.3 at associated percentage manganosite of $47 \% \mathrm{MnO}$ to $26 \% \mathrm{MnO}$, as compared to the rest of the samples which all displayed analyses close to the target bulk slag phase chemistry of $\mathrm{B} 3=1.34$ and $\% \mathrm{MnO}=25$. Therefore, the slag phase analyses for sample $\mathrm{F}$, contained in Table $\mathrm{a}$ in the Appendix, were compared to the equilibrium liquidus slag chemistry calculated within the system of $\mathrm{MgO}-\mathrm{CaO}-\mathrm{SiO}_{2}-\mathrm{MnO}$ using FactSage 6.4 thermochemical software, plotted in Figures 6 and 7.

The analyses data plots in Figures 6 and 7 indicate that slag phase liquidus temperatures were below $1400^{\circ} \mathrm{C}$, even though bulk ore chemistry (illustrated as reduction path line plots for Mamatwan ore in Figure 6 and 7) is of much higher melting point. This disparity in melting point is possible because of formation of monoxide solid solution phase consisting of $\mathrm{MnO}$ and some $\mathrm{MgO}$ (SEM analyses contained in Appendix, Table b), thus resulting in lower levels of $\mathrm{MnO}$ and $\mathrm{MgO}$ in the main oxide phase, enabling its melting to slag at relatively low temperatures. This is an important aspect in manganese ore reduction because $\mathrm{MnO}$ is not reduced by $\mathrm{CO}$ alone, but close proximity of $\mathrm{C}$ to the reduction interface is critically important to maintain sufficiently reducing conditions to drive $\mathrm{MnO}$ reduction (Kleyenstuber, 1979). Slag formation allows for improved contact between the carbon particle surfaces and oxide phases (reduction sites). In addition slag flow allows for renewal of contact interfaces, as compared to stagnant solid particles of ore and carbon.

Figure 5: Slag phase B3 vs. mass\% $\mathrm{MnO}$ in slag

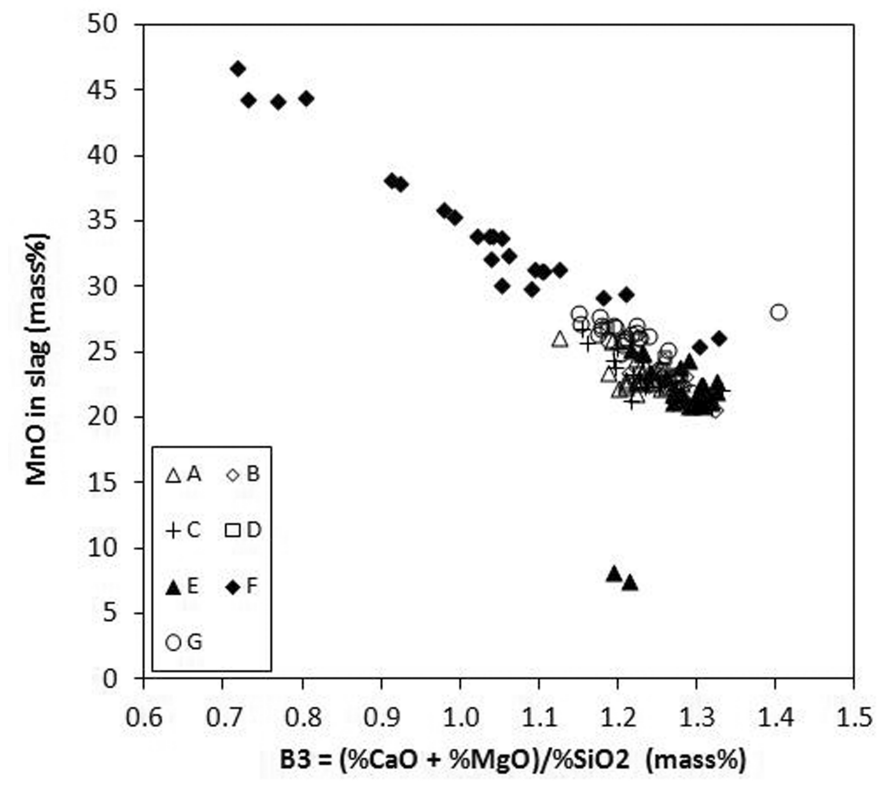




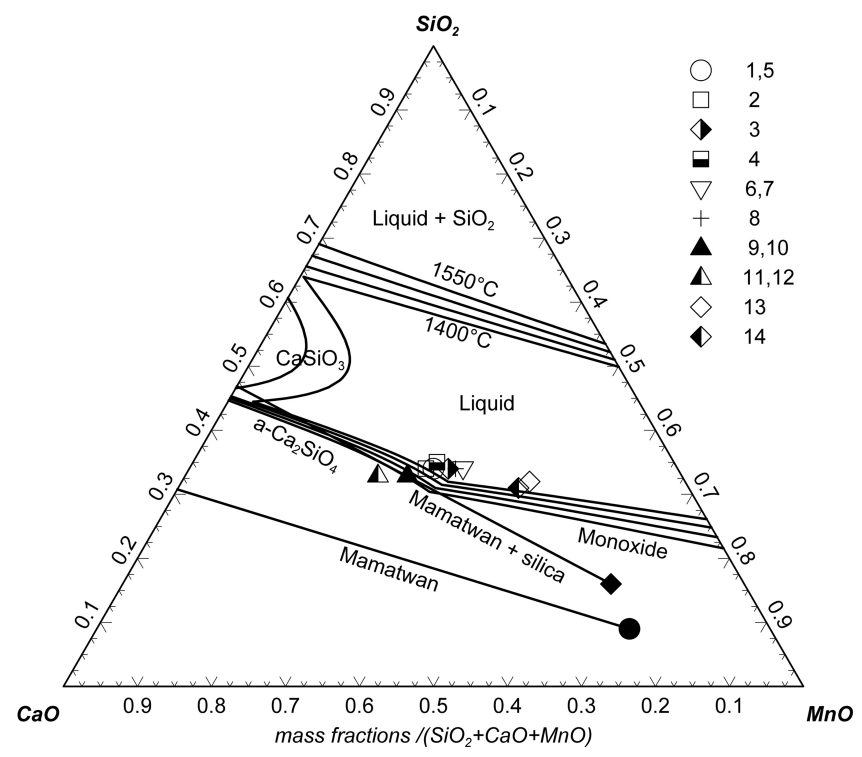

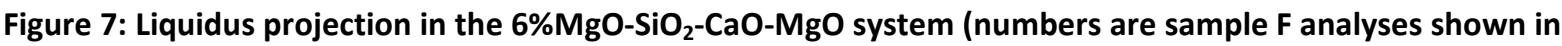
appendix, Table a)

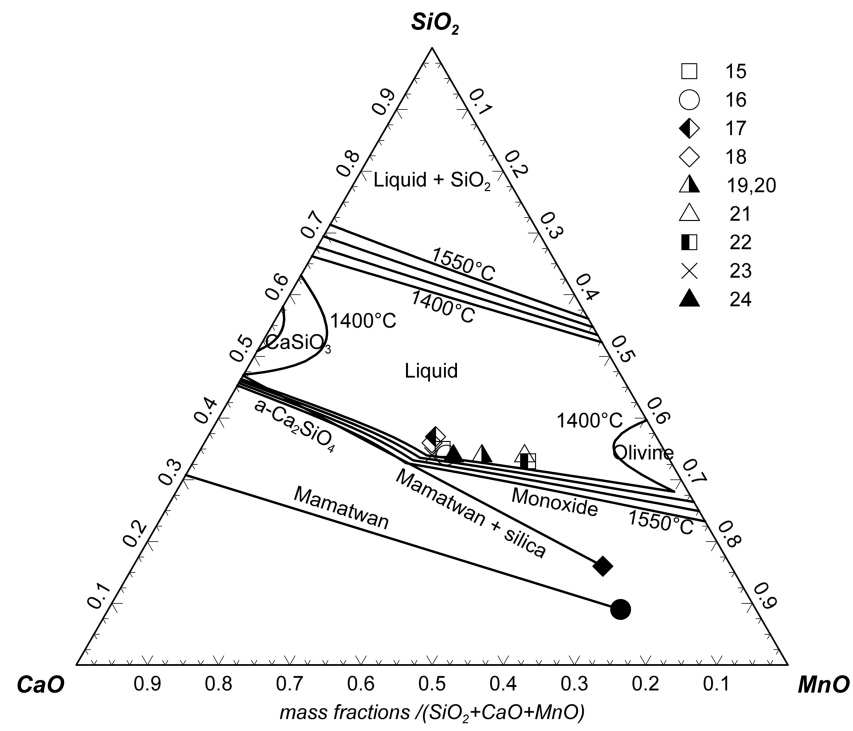

The alloy SEM analyses for all the polished sections are plotted in Figure 8 . It is seen that there is a concentration of analyses at high levels of \% $\mathrm{Mn}(80-90 \%)$ and \% $(6-9 \%)$ for samples A-E and G, whilst sample $\mathrm{F}$ alloy analyses contain maximum $63 \% \mathrm{Mn}$ at $6 \% \mathrm{C}$. Figures 9 and 10 display these cumulative analyses trends for samples A-E and $G$ versus that for sample F. Therefore, similarly to the slag phase analyses in sample $F$, 
alloy phase analyses in this sample displays a broad range of phase chemistry in a development trajectory as compared to that in the rest of the samples, which were concentrated at end-point reaction alloy analyses levels.

Figure 8(a): Alloy phase chemistry (SEM) in samples A-C and F

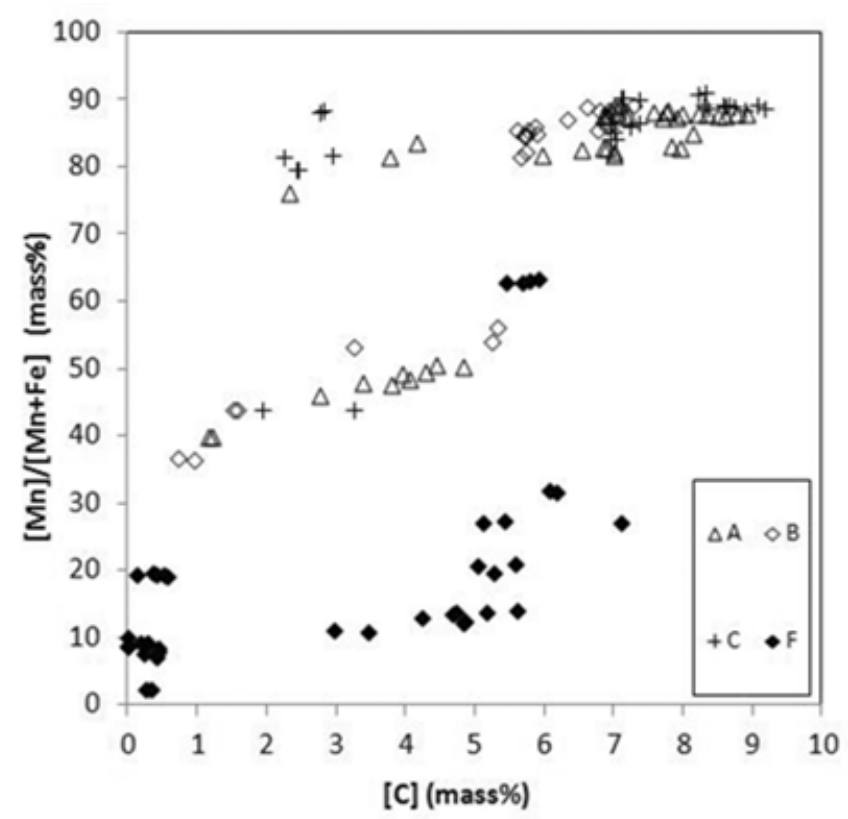

Figure 8(b): Alloy phase chemistry (SEM) in samples D-G

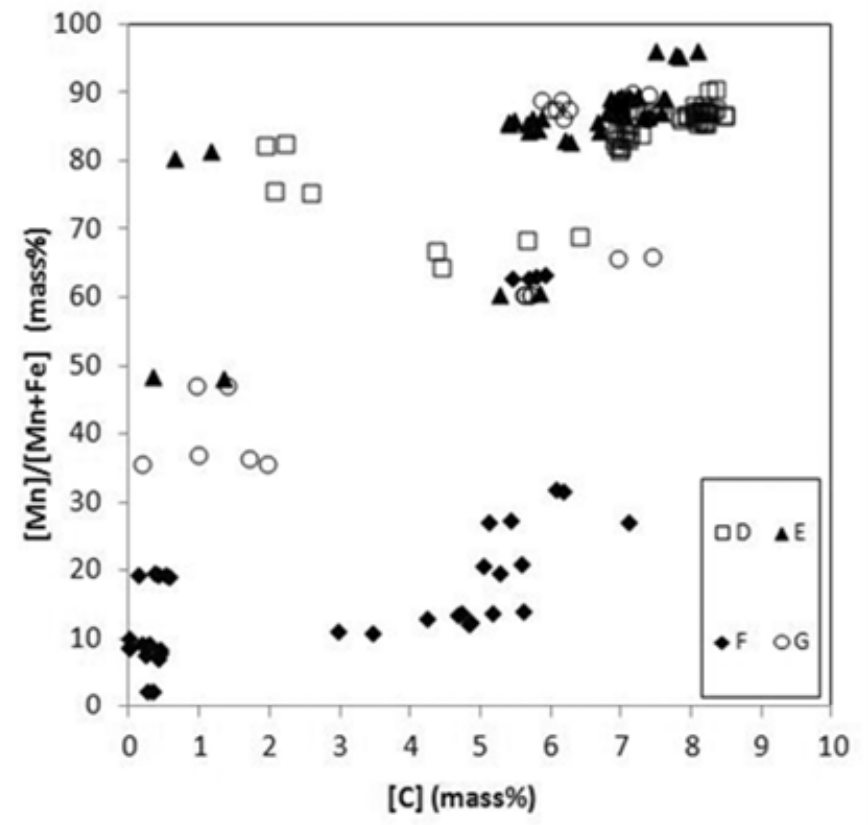




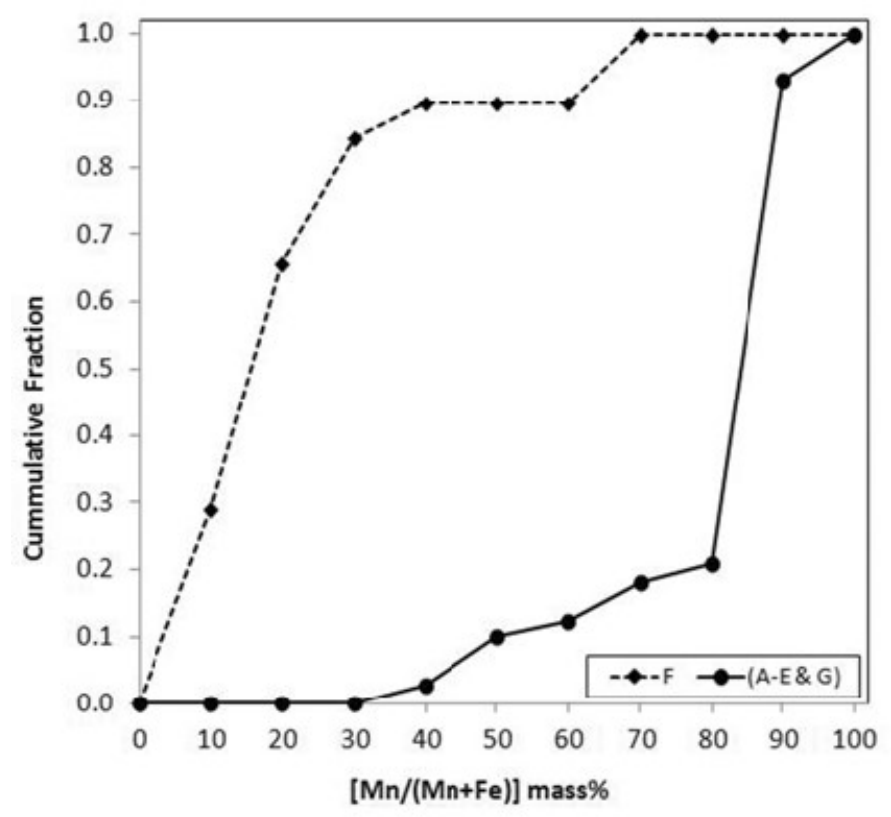

Figure 10: Cumulative alloy phase analyses: \%Carbon in alloy (SEM)

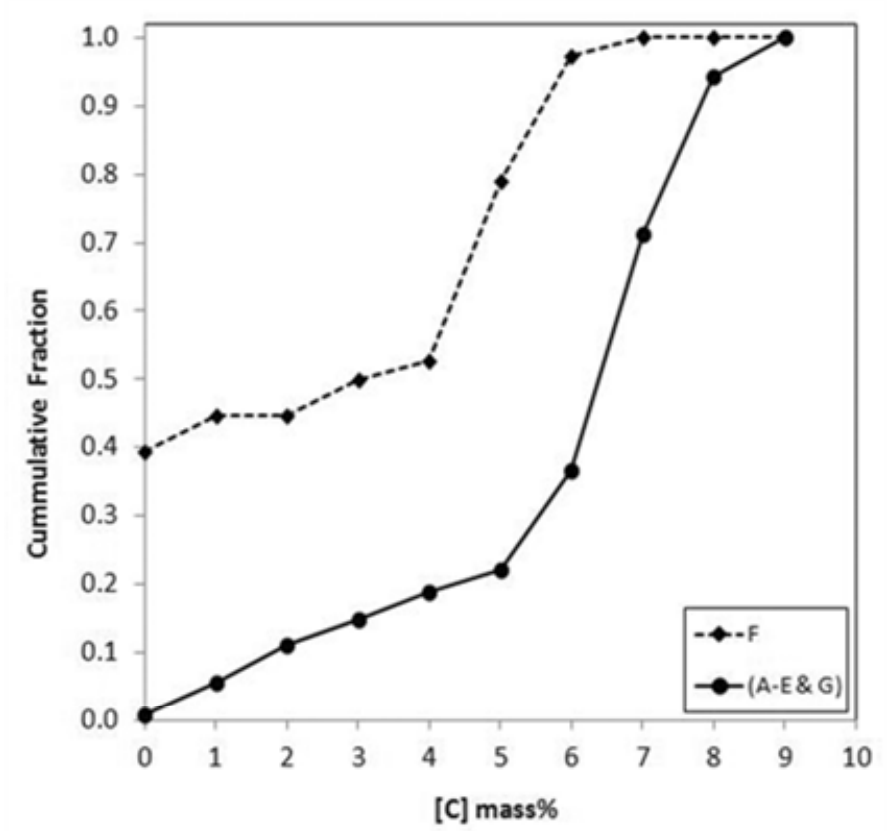

Equilibrium alloy liquidus temperatures were calculated in FactSage 6.4 thermochemical software for sample $F$ analyses, for comparison to the slag liquidus temperatures in Figures 6 and 7. The diagrams in Figure 11 (a-c) illustrate that the alloy liquidus temperatures display a u-shaped trend with increased manganese and carbon content in the alloy beads. The result is that the alloy liquidus temperature is initially high as the alloy beads formed are low in \% $\mathrm{Mn}$ and \%C. Then as reduction proceeds and more manganese is reduced to alloy and carbon dissolved into the alloy the result is a decrease in alloy liquidus temperatures. Comparison of slag phase liquidus temperatures in Figures 6 and 7 to alloy phase liquidus temperatures in Figure 11 indicates that 
the slag phase liquidus temperatures are mostly close to $1400^{\circ} \mathrm{C}$, and alloy phase liquidus temperatures varied from $1500^{\circ} \mathrm{C}$ to $1150^{\circ} \mathrm{C}$, with most results below $1300^{\circ} \mathrm{C}$. Formation of low melting point slag phases will in part contribute to the absence of significant alloy carbon refinement according to reaction (1) because the liquid slag phase closed off original pores in the pre-reduced ore particles, and prevent $\mathrm{CO}_{2}$ access to the alloy phases. In high carbon ferromanganese production in the SAF the bulk of manganese units in the feed mixture is made as lump ore so that slag formation is set by ore chemistry with little possibility of manipulating oxide melting behaviour in the feed mixture (Coetsee et al., 2014). Only when agglomerates such as pellets or sinters are used, may the oxide chemistry be manipulated to limit slag formation to facilitate gas access to alloy beads for reaction (1) to possibly drive carbon refinement.

Figure 11(a): Alloy phase diagram: 0\%Carbon (numbers are sample F analyses shown in appendix, Table c)

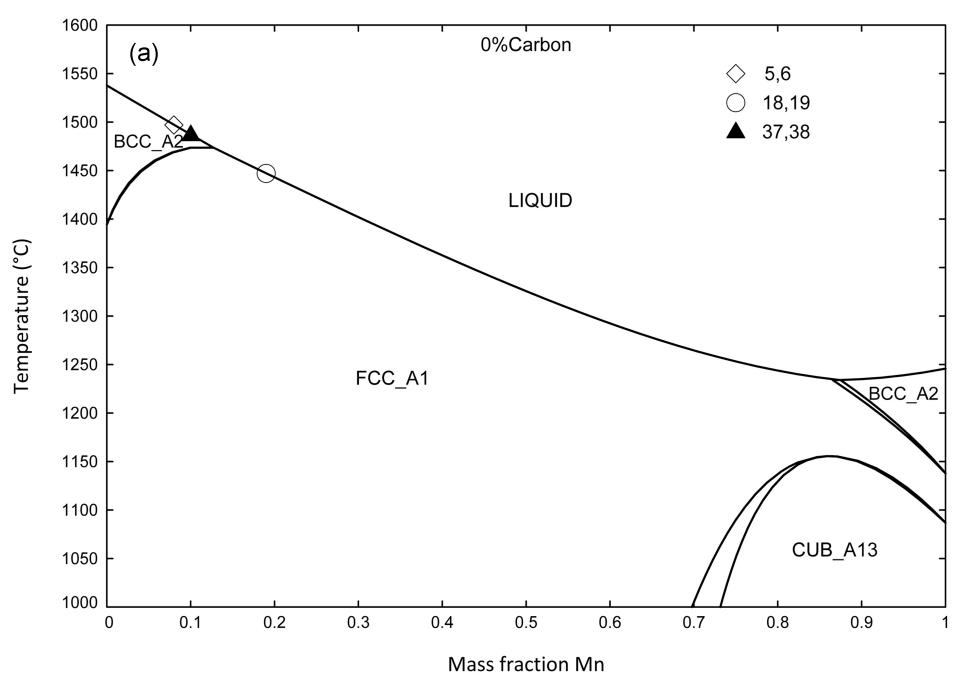

Figure 11(b): Alloy phase diagram: 3\%Carbon (numbers are sample F analyses shown in appendix, Table c)

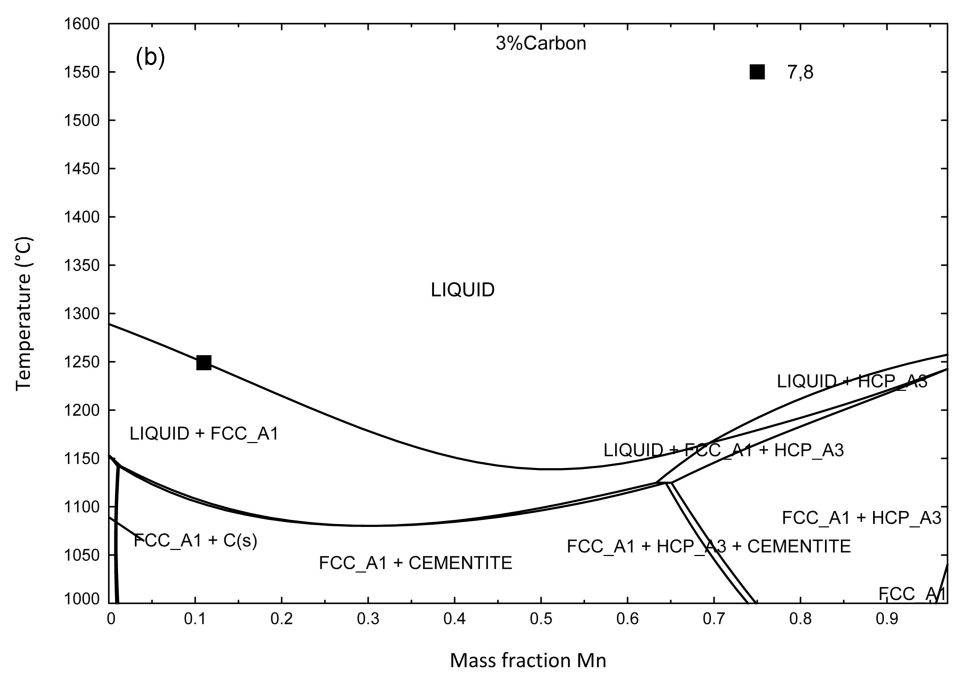


Figure 11(c): Alloy phase diagram: 5\%Carbon (numbers are sample F analyses shown in appendix, Table c)

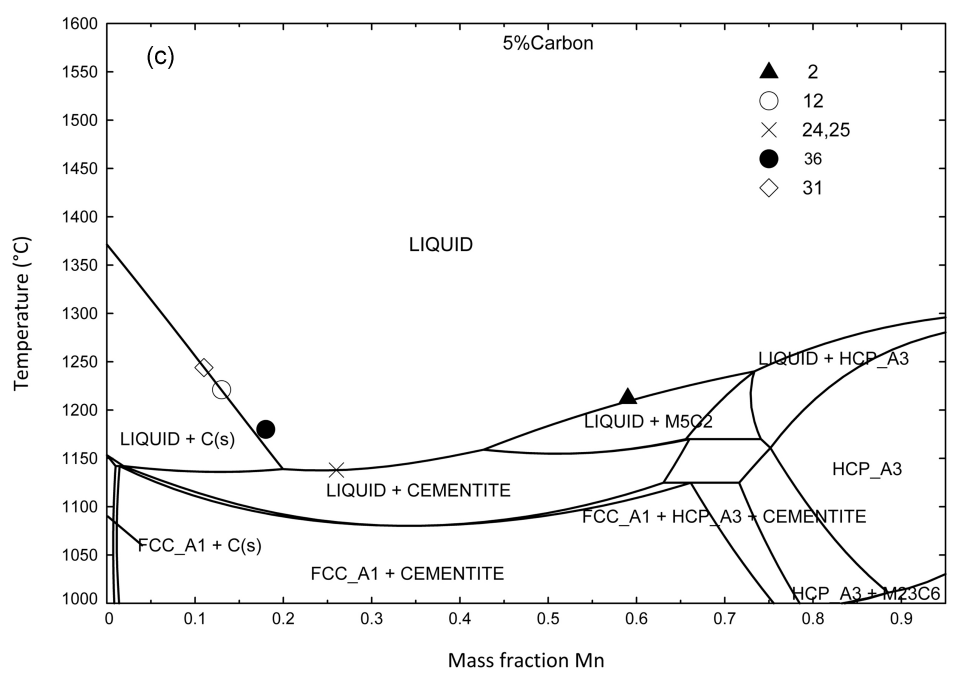

\subsection{Pilot plant furnace alloy composition}

High carbon ferromanganese alloy tapped from the AlloyStream pilot plant furnace contained in the order of $6.5 \% \mathrm{C}$ at a tapping temperature of $1550^{\circ} \mathrm{C}$. This unsaturated level of carbon was in part made possible because the hearth refractories were made of $\mathrm{MgO}$, as compared to carbon refractories used is SAF furnaces. The alloy bath consisted of a reservoir mass of 20 tonnes. However, given the high level of carbon in the feed mixture as compared to the laboratory results discussed above, formation of carbon unsaturated alloy is unexpected. Throughout the pilot plant campaign spanning four months, heap samples were collected for characterisation as reported in detail (Coetsee et al., 2015). In addition, alloy beads (>1 mm diameter) were collected from the heap material and analysed by ICP-OES and LECO. Table 7 illustrates selected heap alloy bead analyses and the associated metal tap alloy analyses from the 7 weeks period in which an ore mixture of $90 \%$ Mamatwan ore and $10 \%$ Wessels ore was used with silica flux and medium volatile thermal coal from Exxaro's Leeuwpan colliery.

It is seen that the two sets of analyses are similar, indicating that little or no refining of carbon or addition of manganese took place as the initially formed alloy beads moved down the solid heap to the metal bath. For comparison to laboratory experimental mixtures in Table 4, the level of carbon addition in the feed mixture is expressed as moles of fixed carbon in coal to moles of reducible oxygen in the ore mixture (reducible oxygen is the moles of oxygen associated with manganese and iron oxides in the ore expressed as $\mathrm{Mn}_{2} \mathrm{O}_{3}$ and $\mathrm{Fe}_{2} \mathrm{O}_{3}$ ). Part of the coal fixed carbon is burnt in the furnace combustion zone, therefore excess carbon beyond $\mathrm{FC} / \mathrm{O}=1.0$ was required in the feed mixture. The level of alloy carbon undersaturation is illustrated in Figure 12 by comparison of the alloy carbon content values from Table 7 to tapped alloy carbon saturation levels at $1550^{\circ} \mathrm{C}$. 
Table 7: Heap alloy bead and tapped alloy analyses

\begin{tabular}{|c|c|c|c|c|c|c|c|c|}
\hline $\begin{array}{l}\text { Sample } \\
\text { Number }\end{array}$ & $\% \mathrm{C}$ & $\% \mathrm{Mn}$ & $\% \mathrm{Fe}$ & $\% \mathrm{Si}$ & $\% \mathrm{P}$ & $\% \mathrm{~S}$ & Total & $\begin{array}{c}{ }^{3} \mathrm{FC} / \mathrm{O} \text { in } \\
\text { feed } \\
\text { mixture }\end{array}$ \\
\hline${ }^{1} \mathrm{~T} 1$ & 6.70 & 78.6 & 14.1 & 0.30 & 0.07 & 0.007 & 99.8 & 1.4 \\
\hline${ }^{2} \mathrm{H} 1$ & 6.57 & 73.0 & 19.0 & 0.18 & 0.10 & 0.019 & 98.9 & \\
\hline T2 & 6.58 & 78.9 & 14.2 & 0.21 & 0.08 & 0.003 & 100.0 & 1.4 \\
\hline $\mathrm{H} 2$ & 6.88 & 76.9 & 15.2 & 0.19 & 0.08 & 0.008 & 99.3 & \\
\hline T3 & 6.75 & 77.8 & 14.8 & 0.36 & 0.10 & 0.007 & 99.8 & 1.5 \\
\hline $\mathrm{H3}$ & 6.67 & 76.7 & 15.6 & 0.03 & 0.11 & 0.004 & 99.1 & \\
\hline T4 & 6.72 & 79.6 & 14.5 & 0.01 & 0.10 & 0.003 & 100.9 & 1.5 \\
\hline $\mathrm{H} 4$ & 6.63 & 79.5 & 11.9 & 0.37 & 0.11 & 0.016 & 98.5 & \\
\hline T5 & 6.73 & 78.6 & 14.8 & 0.09 & 0.12 & 0.004 & 100.3 & 1.6 \\
\hline $\mathrm{H} 5$ & 6.83 & 77.5 & 14.1 & 0.20 & 0.15 & 0.010 & 98.8 & \\
\hline T6 & 6.88 & 79.0 & 14.4 & 0.07 & 0.11 & 0.004 & 100.5 & 1.5 \\
\hline $\mathrm{H7}$ & 7.06 & 79.5 & 13.6 & 0.12 & 0.12 & 0.017 & 100.4 & \\
\hline T7 & 6.69 & 78.9 & 14.4 & $<0.01$ & 0.12 & 0.003 & 100.1 & 1.5 \\
\hline $\mathrm{H7}$ & 6.76 & 73.8 & 19.0 & 0.15 & 0.13 & 0.012 & 99.9 & \\
\hline T8 & 6.79 & 79.5 & 14.5 & $<0.01$ & 0.11 & 0.003 & 100.9 & 1.5 \\
\hline $\mathrm{H} 8$ & 6.69 & 73.0 & 18.8 & 0.15 & 0.17 & 0.010 & 98.8 & \\
\hline T9 & 6.64 & 79.1 & 14.4 & 0.04 & 0.13 & 0.003 & 100.3 & 1.6 \\
\hline $\mathrm{H} 9$ & 7.07 & 83.8 & 8.4 & 0.19 & 0.09 & 0.009 & 99.6 & \\
\hline T10 & 6.78 & 78.1 & 14.6 & 0.04 & 0.12 & 0.003 & 99.6 & 1.6 \\
\hline $\mathrm{H} 10$ & 6.86 & 79.3 & 13.3 & 0.19 & 0.13 & 0.008 & 99.8 & \\
\hline T11 & 6.58 & 78.1 & 14.3 & 0.13 & 0.12 & 0.006 & 99.2 & 1.6 \\
\hline H11 & 6.33 & 72.2 & 19.9 & 0.14 & 0.16 & 0.010 & 98.7 & \\
\hline T12 & 5.77 & 78.0 & 15.4 & 0.02 & 0.15 & 0.001 & 99.3 & 1.6 \\
\hline $\mathrm{H} 2$ & 6.51 & 73.7 & 17.8 & 0.38 & 0.22 & 0.013 & 98.6 & \\
\hline T13 & 6.12 & 78.1 & 15.3 & 0.07 & 0.18 & 0.001 & 99.8 & 1.6 \\
\hline $\mathrm{H} 13$ & 6.75 & 77.1 & 15.5 & 0.18 & 0.17 & 0.009 & 99.7 & \\
\hline
\end{tabular}

${ }^{1}$ Tapped alloy $=\mathrm{T} ;{ }^{2}$ Heap alloy $=\mathrm{H} ;{ }^{3}$ Fixed carbon to reducible oxygen

Figure 13 indicates the liquidus temperatures (the temperature of initial solid phase formation in the form of either graphite or $\mathrm{M}_{7} \mathrm{C}_{3}$ ) of the alloy compositions in Table 7. These values indicate that the temperature of formation of the initial alloy is in the order of $1300^{\circ} \mathrm{C}$ to $1400^{\circ} \mathrm{C}$, significantly lower than the alloy bath temperature of $1550^{\circ} \mathrm{C}$. In addition, the partial pressure of $\mathrm{CO}$ at the top of the heap is unlikely to be at $100 \%$ given the material feed mixture contained Mamatwan ore which calcined, and coal which devolatilised at the heap surface. Levels of CO below $100 \%$ at the heap surface, unlike the high CO levels in the laboratory experiments reported here and in the coke bed of the SAF, will facilitate lower levels of carbon in primary alloy formation. In this way, at lower levels of reaction temperatures and lower \%CO at the top of the heap in the AlloyStream process, with no or little subsequent carbon addition to the primary alloy, an undersaturated carbon alloy product was tapped from the AlloyStream furnace. 
Figure 12: Alloy \%C in heap alloy beads vs. tapped alloy vs. tapped alloy saturation at $1550^{\circ} \mathrm{C}$

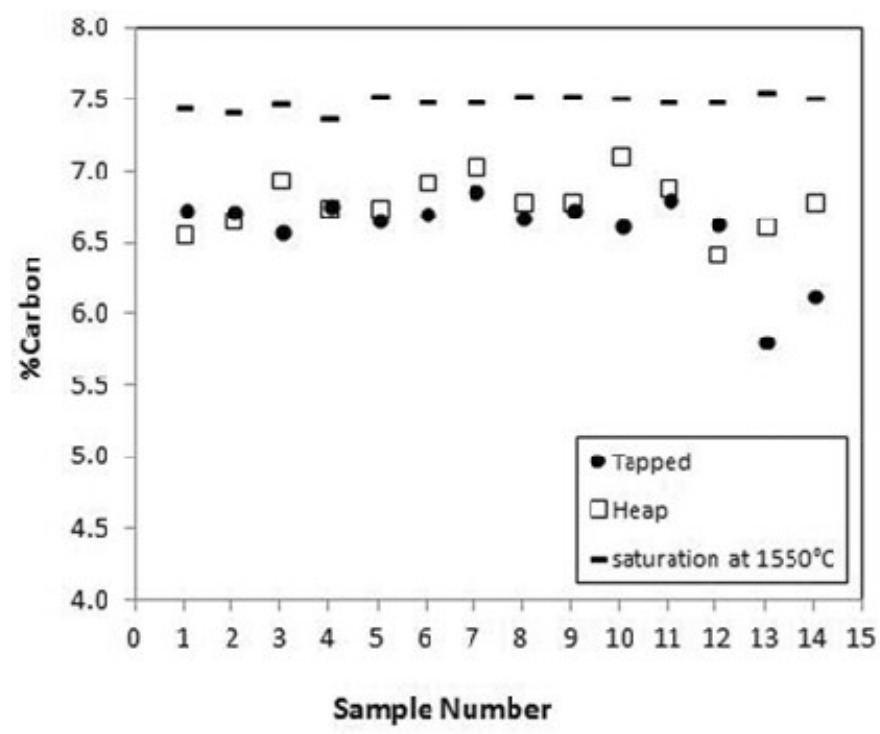

Figure 13: Liquidus temperatures calculated for heap alloy beads and tapped alloy compositions

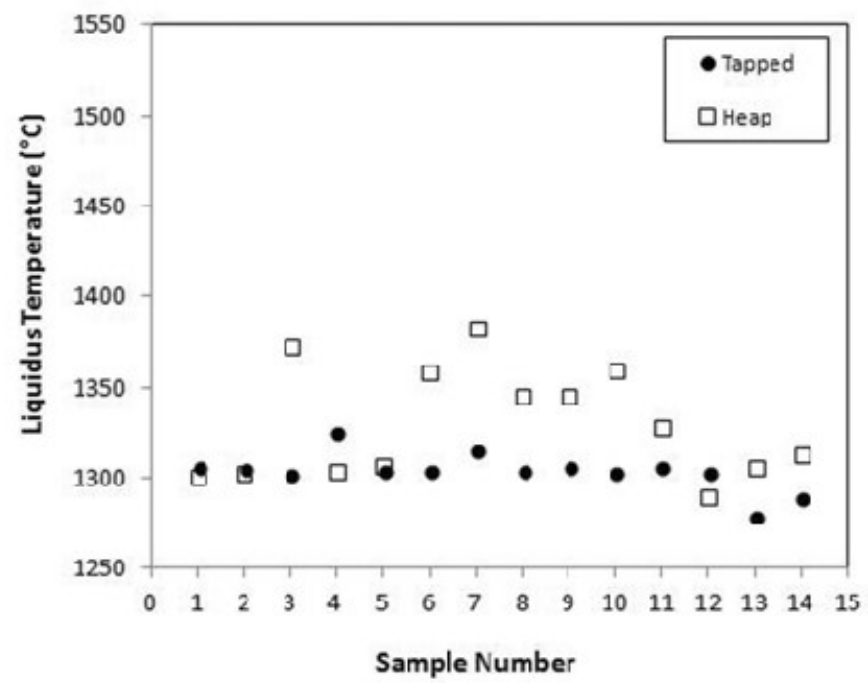




\section{Conclusions}

- The main objective of this research was to test the feasibility of producing medium carbon ferromanganese in the carbothermic reduction of Mamatwan ore. The results confirm that medium carbon ferromanganese was not formed as the endpoint alloy product when carbon reductant was used, even when carbon reductant addition levels were well below stoichiometry $(C / O=1.0)$. However, a range of alloy carbon content levels was measured in uncoalesced alloy areas at $0 \% \mathrm{C}$ to $9 \% \mathrm{C}$, for the feed mixture carbon addition levels tested ( $\mathrm{C} / \mathrm{O}=0.79,0.94$ and 1.08$)$.

- The effect of increased temperature from $1450^{\circ} \mathrm{C}$ to $1550^{\circ} \mathrm{C}$ on reduction rate was dominant. The effect of carbon addition was only observed at the lower level of carbon addition of $\mathrm{C} / \mathrm{O}$ of 0.79 , as compared to carbon additions at $\mathrm{C} / \mathrm{O}$ of 0.94 and 1.08 , respectively.

- Results from partially reacted samples containing high basicity Mamatwan ore confirmed the acidic phase chemistry of the glass phase formed prior to coalescence of oxide phases into a bulk slag, at $\mathrm{B} 3=0.7-1.3$. (Figure 5); and that the bulk of reduction reactions occur below $1450^{\circ} \mathrm{C}$ with $\mathrm{CO}$ as the main gaseous product. Thus, heating of the sample mixture to higher temperatures was only required to attain slag-metal separation.

- Formation of low melting point slag phases may explain the absence of significant alloy carbon refinement by $\mathrm{CO}_{2}$ gas because liquid slag phase closed off the original pores in the pre-reduced ore to block gas access to the alloy phases contained within pre-reduced ore particles.

- Although the endpoint alloy products in the laboratory tests were high carbon ferromanganese, alloy tapped at $1550^{\circ} \mathrm{C}$ from the AlloyStream pilot plant was not carbon saturated (containing $6.5 \% \mathrm{C}$ ). This lower level carbon ferromanganese product was made possible because of primary alloy bead formation at $1300^{\circ} \mathrm{C}$ to $1400^{\circ} \mathrm{C}$ and/or less than $100 \% \mathrm{CO}$ gas composition formed at the top of the heap.

\section{Acknowledgements}

The author thanks Exxaro Resources for permission to publish this paper. Appreciation is expressed to Mintek personnel for conducting SEM analyses. 


\section{Appendix}

Table a: Slag phase analyses (SEM) in Sample F

\begin{tabular}{|c|c|c|c|c|c|c|c|c|c|}
\hline Number & $\% \mathrm{MgO}$ & $\% \mathrm{Al}_{2} \mathrm{O}_{3}$ & \%FeO & $\% \mathrm{MnO}$ & $\% \mathrm{CaO}$ & $\mathrm{SiO}_{2}$ & Total & *B2 & *B3 \\
\hline 1 & 85 & 0 & 30 & 6 & .06 & 1.59 & 97.0 & 1.0 & 1.1 \\
\hline 2 & 3.56 & 0 & 0.62 & 30.15 & 31.28 & 31.57 & 97.2 & 1.0 & 1.1 \\
\hline 3 & 5.00 & 0.10 & 0.43 & 31.58 & 28.88 & 31.91 & 97.9 & 0.9 & 1.1 \\
\hline 4 & 5.09 & 0.19 & 0.21 & 30.20 & 29.83 & 31.03 & 96.5 & 1.0 & 1.1 \\
\hline 5 & 4.27 & 0.08 & 0.14 & 34.82 & 26.51 & 31.42 & 97.2 & 0.8 & 1.0 \\
\hline 6 & 1.57 & 0.11 & 0.02 & 45.64 & 20.12 & 30.25 & 97.7 & 0.7 & 0.7 \\
\hline 7 & 1.75 & 1.66 & 0.13 & 42.32 & 21.07 & 28.35 & 95.3 & 0.7 & 0.8 \\
\hline 8 & 4.23 & 0 & 0.01 & 32.68 & 28.38 & 31.31 & 96.6 & 0.9 & 1.0 \\
\hline 9 & 5.32 & 0 & 0.32 & 36.41 & 23.29 & 30.99 & 96.3 & 0.8 & 0.9 \\
\hline 10 & 4.62 & 0 & 0.40 & 42.94 & 18.21 & 31.21 & 97.4 & 0.6 & 0.7 \\
\hline 11 & 4.73 & 0.07 & 0.19 & 42.51 & 18.53 & 30.26 & 96.3 & 0.6 & 0.8 \\
\hline 12 & 2.88 & 0 & 0 & 28.61 & 34.70 & 31.03 & 97.2 & 1.1 & 1.2 \\
\hline 13 & 2.87 & 0.04 & 0.37 & 28.64 & 34.76 & 31.82 & 98.5 & 1.1 & 1.2 \\
\hline 14 & 2.36 & 0 & 0.37 & 25.23 & 38.47 & 30.76 & 97.2 & 1.3 & 1.3 \\
\hline 15 & 4.12 & 0.12 & 0.59 & 33.53 & 26.29 & 30.64 & 95.3 & 0.9 & 1.0 \\
\hline 16 & 4.47 & 0 & 0.38 & 32.82 & 28.18 & 31.45 & 97.3 & 0.9 & 1.0 \\
\hline 17 & 4.20 & 0.10 & 0.14 & 32.81 & 28.06 & 31.55 & 96.9 & 0.9 & 1.0 \\
\hline 18 & 4.43 & 0 & 0 & 32.45 & 28.31 & 31.10 & 96.3 & 0.9 & 1.1 \\
\hline 19 & 4.41 & 0 & 0.11 & 31.79 & 29.76 & 32.85 & 98.9 & 0.9 & 1.0 \\
\hline 20 & 4.29 & 0.31 & 0.23 & 30.22 & 30.18 & 31.48 & 96.7 & 1.0 & 1.1 \\
\hline 21 & 6.41 & 0.03 & 2.53 & 28.60 & 27.68 & 32.38 & 97.6 & 0.9 & 1.1 \\
\hline 22 & 6.77 & 0 & 1.29 & 28.49 & 28.19 & 32.06 & 96.8 & 0.9 & 1.1 \\
\hline 23 & 4.67 & 0.04 & 0.34 & 37.20 & 24.08 & 31.45 & 97.8 & 0.8 & 0.9 \\
\hline 24 & 2.26 & 0.18 & 0.90 & 25.06 & 39.27 & 31.88 & 99.6 & 1.2 & 1.3 \\
\hline
\end{tabular}

6. $* \mathrm{~B} 2=\left(\% \mathrm{CaO} / \% \mathrm{SiO}_{2}\right) ; \mathrm{B} 3=(\% \mathrm{CaO}+\% \mathrm{MgO}) / \% \mathrm{SiO}_{2}$

Table b: Monoxide phase analyses (SEM) in Sample F

\begin{tabular}{|c|c|c|c|c|c|c|c|}
\hline Number & $\% \mathrm{MgO}$ & $\% \mathrm{Al}_{2} \mathrm{O}_{3}$ & $\% \mathrm{FeO}$ & $\% \mathrm{MnO}$ & $\% \mathrm{CaO}$ & $\% \mathrm{SiO}_{2}$ & Total \\
\hline 1 & 3.98 & 0.11 & 0.81 & 91.48 & 1.13 & 0.23 & 97.7 \\
\hline 2 & 4.41 & 0.07 & 0.89 & 90.97 & 1.52 & 0.18 & 98.0 \\
\hline 3 & 3.03 & 0.16 & 0.38 & 92.37 & 0.72 & 0.30 & 97.0 \\
\hline 4 & 2.93 & 0.20 & 0.35 & 94.23 & 0.87 & 0.27 & 98.9 \\
\hline 5 & 3.73 & 0.16 & 0.70 & 93.02 & 0.75 & 0.37 & 98.7 \\
\hline 6 & 3.49 & 0.02 & 0.74 & 92.73 & 0.57 & 0.40 & 97.9 \\
\hline 7 & 4.68 & 0.15 & 0.90 & 89.93 & 2.85 & 0.21 & 98.7 \\
\hline 8 & 4.82 & 0.31 & 0.26 & 88.71 & 2.64 & 0.53 & 97.3 \\
\hline 9 & 2.24 & 0.08 & 0.56 & 89.87 & 3.54 & 0.45 & 96.7 \\
\hline 10 & 2.43 & 0.31 & 0.18 & 90.45 & 3.17 & 0.34 & 96.9 \\
\hline
\end{tabular}


Table c: Alloy analyses (SEM) in Sample F

\begin{tabular}{|c|c|c|c|c|c|c|c|}
\hline Number & $\% \mathrm{C}$ & $\% \mathrm{Fe}$ & $\% \mathrm{Mn}$ & $\% \mathrm{P}$ & $\% \mathrm{~S}$ & $\% \mathrm{Si}$ & Total \\
\hline 1 & 6 & 35.8 & 60.3 & 0.02 & 0.01 & 0.01 & 101.9 \\
\hline 2 & 6 & 35.9 & 60.7 & 0.01 & 0.01 & 0.01 & 102.2 \\
\hline 3 & 6 & 35.9 & 61.0 & 0.01 & 0.00 & 0.01 & 102.9 \\
\hline 4 & 6 & 35.7 & 61.3 & 0.01 & 0.00 & 0.03 & 103.2 \\
\hline 5 & 0 & 93.8 & 7.9 & 0.05 & 0.01 & 0.01 & 102.1 \\
\hline 6 & 0 & 94.0 & 7.9 & 0.06 & 0.01 & 0.00 & 102.4 \\
\hline 7 & 3 & 88.6 & 11.0 & 0.09 & 0.05 & 0.03 & 102.8 \\
\hline 8 & 4 & 88.5 & 10.8 & 0.09 & 0.05 & 0.03 & 103.0 \\
\hline 9 & 0 & 91.9 & 9.3 & 0.02 & 0.01 & 0.01 & 101.5 \\
\hline 10 & 0 & 92.6 & 9.2 & 0.03 & 0.00 & 0.01 & 102.1 \\
\hline 11 & 4 & 84.8 & 12.7 & 0.06 & 0.01 & 0.0 & 101.9 \\
\hline 12 & 5 & 83.9 & 13.4 & 0.01 & 0.00 & 0.00 & 102.6 \\
\hline 13 & 6 & 83.5 & 13.5 & 0.02 & 0.01 & 0.01 & 102.8 \\
\hline 14 & 0 & 92.1 & 8.6 & 0.22 & 0.01 & 0.01 & 101.3 \\
\hline 15 & 0 & 93.1 & 7.2 & 0.14 & 0.01 & 0.01 & 100.9 \\
\hline 16 & 0 & 98.0 & 2.3 & 0.01 & 0.01 & 0.00 & 100.6 \\
\hline 17 & 0 & 98.0 & 2.3 & 0.02 & 0.01 & 0.01 & 100.6 \\
\hline 18 & 0 & 81.7 & 19.8 & 0.08 & 0.00 & 0.38 & 102.3 \\
\hline 19 & 0 & 81.2 & 19.6 & 0.12 & 0.00 & 0.40 & 101.8 \\
\hline 20 & 7 & 70.6 & 26.2 & 0.08 & 0.01 & 0.08 & 104.3 \\
\hline 21 & 0 & 80.2 & 19.3 & 0.35 & 0.01 & 0.94 & 100.9 \\
\hline 22 & 1 & 80.8 & 19.0 & 0.37 & 0.00 & 1.01 & 101.7 \\
\hline 23 & 1 & 80.7 & 19.5 & 0.41 & 0.00 & 0.93 & 102.1 \\
\hline 24 & 6 & 70.4 & 26.6 & 0.01 & 0.01 & 0.03 & 102.7 \\
\hline 25 & 5 & 70.8 & 26.3 & 0.01 & 0.01 & 0.01 & 102.3 \\
\hline 26 & 5 & 83.6 & 13.2 & 0.01 & 0.01 & 0.01 & 101.6 \\
\hline 27 & 5 & 83.0 & 13.3 & 0.01 & 0.00 & 0.00 & 101.1 \\
\hline 28 & 0 & 91.0 & 8.6 & 0.02 & 0.01 & 0.01 & 99.7 \\
\hline 29 & 0 & 91.7 & 8.7 & 0.01 & 0.01 & 0.01 & 100.4 \\
\hline 30 & 5 & 83.6 & 11.9 & 0.01 & 0.00 & 0.01 & 100.4 \\
\hline 31 & 5 & 84.0 & 11.5 & 0.00 & 0.01 & 0.01 & 100.4 \\
\hline 32 & 7 & 68.4 & 31.7 & 0.14 & 0.01 & 0.85 & 107.6 \\
\hline 33 & 7 & 69.5 & 32.5 & 0.13 & 0.01 & 0.80 & 109.5 \\
\hline 34 & 5 & 75.6 & 19.8 & 0.02 & 0.01 & 0.01 & 100.6 \\
\hline 35 & 5 & 70.9 & 18.8 & 1.25 & 0.01 & 0.03 & 96.3 \\
\hline 36 & 5 & 74.4 & 18.0 & 0.29 & 0.01 & 0.07 & 98.0 \\
\hline 37 & 0 & 88.9 & 10.0 & 0.42 & 0.00 & 1.36 & 100.7 \\
\hline 38 & 0 & 89.3 & 9.2 & 0.41 & 0.00 & 1.64 & 100.8 \\
\hline
\end{tabular}




\section{References}

Bale, C.W., Chartrand, P., Degterov, S.A., Eriksson, G., 2002, "FactSage thermochemical software and databases." CALPHAD, 26, pp. 189-228.

Coetsee, T., Zietsman, J., Pistorius, P.C., 2014. "Predicted effect of ore composition on slag formation in manganese ore reduction." Mineral Processing and Extractive Metallurgy, 123, pp. 141-147.

Coetsee, T., Reinke, C., Nell, J., Pistorius, P.C., 2015. "Reduction mechanisms in manganese ore reduction." Metallurgical Transactions B, 46B, pp. 2534-2552.

Eric, R.H., Burucu, E., 1992. "The mechanism and kinetics of the carbothermic reduction of Mamatwan manganese ore fines." Minerals Engineering, 5, pp. 795-815.

Fourie, L.J., 2000, “Metal containing compound reduction and melting process.” US patent 6146437.

Habashi, F. (ed.), 1997, Handbook of Extractive Metallurgy, vol. 1, p. 435. Weinheim: Wiley-VCH.

Kleyenstuber, A.S.E., 1979, M.Sc. thesis (in Afrikaans: 'n Mineralogiese Ondersoek van Hoë-temperatuurreduksieprodukte van Mangaanerts vanuit die Mamatwanmyn, Kalaharimangaanveld), Rand Afrikaans University, Johannesburg, South Africa.

Koursaris, A., Kleynstuber, A.S.E., Finn, C.W.P., 1983. "A mineralogical investigation of the reduction of Mamatwan manganese ore with carbon." Spec. Publ. Geol. Soc. S. Afr., 7, pp. 375-382.

Koursaris, A., See, J. B., 1979. "Discussion: Reactions in the production of high-carbon ferromanganese from Mamatwan ore." .J S. Afr. Inst. Min. Metall., 79, pp. 306-309.

Terayama, K., Ikeda, M., 1985. "Study on reduction of MnO with carbon by effluent gas analysis method." Transactions of the Japan Institute of Metals, 26, pp. 108-114. 